\title{
Research on Power Knowledge Model Based on Group Wisdom
}

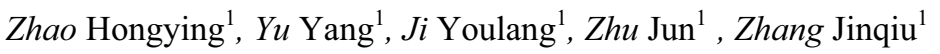 \\ ${ }^{1}$ Electric Research Institute, Jiangsu Electric Power Company, Nanjing 210019, China
}

\begin{abstract}
This study described the plan of knowledge management and crowd innovation for Jiangsu electric company based on literature analysis on crowd innovation research and investigation of the company's innovation state as well as its electric service. A knowledge management system was designed for all the experts in electric field, all the workers and the customers in order to achieve crowd innovation. This system was designed based on the consideration of innovation process, evaluation and motivation, and it is implemented with the Web 2.0 technology.
\end{abstract}

\section{Introduction}

The public innovation model has been tested in practice and is considered to be the key to improving the efficiency of corporate innovation [1]. Under the strategic principle of "One Strong Three Excellent" (Strongly Constructed Power Grid, Excellent Assets, Excellent Service, and Outstanding Achievements) of State Grid Power, State Grid Jiangsu Electric has implemented State Grid's "Innovation, Creation, and Entrepreneurship" requirements, insisting that "The development path of innovation, strategy, and time is the first to strengthen the innovation management system and the overall innovation culture. It has established the "four-wide" innovation concept of "full-factor, fullservice, full-staff, and full-scale collaboration" and has made clear innovations. The direction, through the creation of a comprehensive and collaborative innovation atmosphere, supplemented by a number of initiatives in platform support and policy management, continues to drive the company's overall innovation and development, making it a truly endogenous driving force for strong transformation.

On the basis of discussing the theory of the crowdbuilding mode, this article takes the innovation and development of the Jiangsu Power Company as an example, and elaborates on how the crowd-building mode is combined with information methods and has been applied and achieved results in practice. Specifically, on the basis of the overall innovation plan, Jiangsu State Power of the State Grid integrates the resources and needs of internal power experts, front-line employees, and external power customers, and creates a cross-professional, cross-regional knowledge innovation platform to share knowledge. Pass experience, apply breakthrough mode to seek breakthroughs and innovations from practice, enhance enterprise's marketing services in all directions, enhance corporate image, and improve customer satisfaction.

\section{Related work}

The history of human history has been inseparable from the word innovation. From drill fires to household appliances, from radio radio to VR, every step of scientific creation of technological innovation is a disruptive "unheard of", and every company that can capture disruptive technologies has therefore acquired in the business world. Great success. However, this traditional innovation model is often inefficient, and the reason for this is that it does not meet the two major competencies of innovation literacy: one is the lack of driving force for exploration, and the other is a relatively narrow transmission channel [2].

Crowd Innovation came into being. As an extension of open innovation, the "public innovation" model has the fundamental difference from the traditional innovation model in that it breaks through the barriers to the innovation category, mobilizes the enthusiasm of the internal and external public, and expands the source of creativity. Professor Chesbrough, founder of Open Innovation, believes that an open environment can better help companies integrate internal and external resources, create an interactive, intersecting, divergent ideological atmosphere, and greatly increase the probability of successful innovation [3]. The theory of complex adaptive system (CAS) mentioned that the diversity of intelligence resources caused by individual differences has provided a boost to knowledge innovation and intelligence emergence, and has become one of the important sources of innovative new transmission channels [4]. Another important source is external resources and information. In 2013, China introduced the "Enterprise Innovation Capability Evaluation Index System" draft for consultation. One of the indicators' collaborative innovation capabilities emphasizes the importance of the cooperation between industry, universities, and research institutes, and encourages the 
integration of resources such as collaborative innovation and technology introduction and digestion. Western innovation management practices go even further, and their understanding and application of "open style" have long since escaped the directly linked partners. For example, GE's "Ecomagination Challenge", through cofunding with VCs to fund innovative companies with innovative ideas, has brought about a low-cost, highefficiency, GE social responsibility. The results of innovation [3]. In particular, it is worth noting that large companies with large profits and large markets often do not give up their mature products and achievements in order to try out subversive breakthroughs, but this type of cooperation in investment financing can avoid such risks. Taken together, the crowd-sourced model breaks through the conceptual boundary of the internal and external environment, and its openness can be continuously penetrated according to requirements, reducing the intangible costs to a considerable extent.

Another important feature of the crowd-sourced model is the close connection with the Internet [5]. The innovation of Internet technology has allowed explosive expansion of information volume. Through the storage, processing, sharing, and integration of huge amounts of information, companies can use the external environment more closely. In this context, Song Gang and Zhang Nan (2009) proposed the innovation 2.0 theory. They believe that through the development of information and communication technologies and their integration with people's lifestyles, working methods, and organizational methods, one is based on knowledge and information. The core society is being formed, and the innovation model based on traditional laboratories and scientific researchers is being subverted, and it has turned to the user-centered, employee-centered, masscentered innovation 2.0 model [5]. Web 2.0 is the embodiment of innovation 2.0 in the field of Internet. The purpose of the organization's choice of Web 2.0 is to look at the "collective wisdom" it uses to integrate open innovation. Its functions range from increasing intimacy with users to expanding the internal knowledge management system. [6]. User-led is the core of the web2.0 environment. This positioning allows the leading community in crowd-sourced space to transition from the corporate government to the public, promoting the initial seeding stage of the creative platform, and even linking education and training, social media, and attracting talents. And other aspects [7]. Liu Zhiying and other scholars (2015) proposed the communitydevelopment-market (CDM) conceptual model of the crowd-building model [2]. That is to say, the web2.0 platform serves three functions: First, Knowledge community, where the masses gain knowledge sharing; Second, the development platform, the public's innovation needs and collaborative innovation can be achieved in the interactive function; the last is the technology market, promote technology flow, form an online trading market. In the final analysis, Internet technology is a human-driven knowledge management network. This is particularly important for technologybased industries.
The technological innovation in the power industry is inseparable from four key words: safety, economy, cleanliness and continuity. Due to the universality of the audience in the energy industry, the advantages of web2.0 technology are more prominent. The community interaction function brings relatively symmetrical information communication channels to scientific research work, company employees and ordinary consumers. In addition to the concept of open innovation above, we undertake the scientific knowledge of consumer's electric energy knowledge, further fulfill corporate social responsibility and expand the possibility of innovation of the people. Web2.0 technology, as a mature Internet product, is bound to be the best platform and mainstream trend for enterprise organizations with knowledge and technology as the core application of crowd-building space.

\subsection{Knowledge innovation process}

The knowledge creation process is divided into creative communication process, creative refinement process, and creative reward process, as shown in Figure 1.

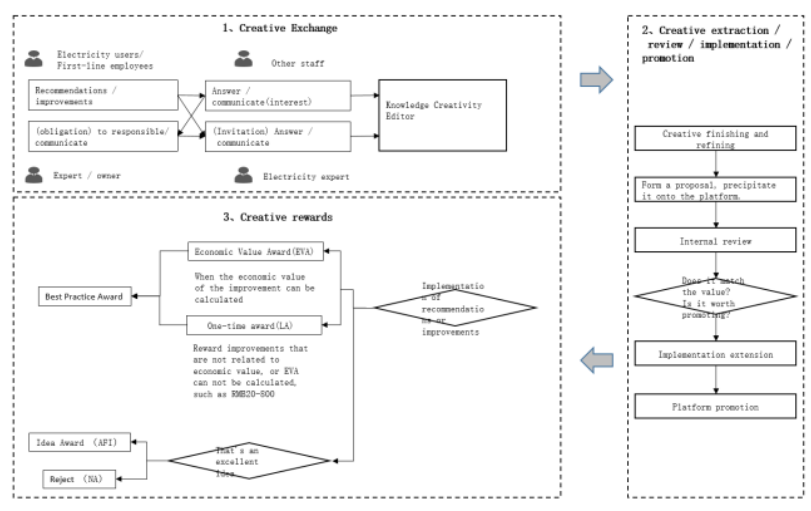

Fig. 1 China National Network Jiangsu Electric Power Knowledge Creation Process

\subsection{Knowledge innovation mechanism}

The State Grid Jiangsu Electric Power Knowledge Innovation Evaluation System is based on the overall innovation evaluation mechanism of Jiangsu Electric Power Company on the State Grid and is designed as follows.

\subsubsection{Knowledge Organizational Structure Evaluation}

The Corporate Innovation Management Committee is responsible for the leadership of innovation evaluation.

The internal evaluation organization is an organization that will be set up in the future evaluation process. It is mainly responsible for the extraction, review, implementation, and promotion of ideas, and is mainly composed of experts in various fields. 


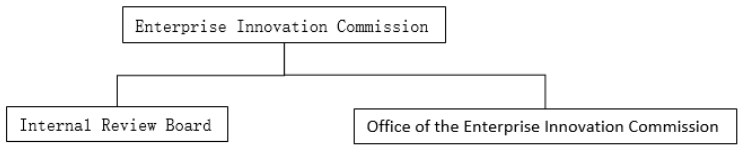

Fig. 2 Knowledge and organization structure of Jiangsu Electric Power Network

\subsubsection{Knowledge Creation Evaluation Organization's Responsibility}

The company's innovation management committee is responsible for the leadership of innovation evaluation. The main responsibilities include: leading the company's innovation evaluation work, coordinating and resolving major problems in the evaluation work; approving the company's innovation work evaluation plan; approving the company's innovation work evaluation index system; reviewing and approving the company's innovation work Evaluation report.

The Office of Corporate Innovation Management Committee (established in the branch of the Enterprise Association) is responsible for organizing the company's innovation evaluation. Its main responsibilities include: formulating (revising) and releasing the evaluation index system of the company's innovation work; formulating the evaluation plan for the company's innovation work and organizing the company's innovation work Evaluation; compiles and publishes evaluation reports on company innovation work; organizes the development of improvement measures for evaluation issues; and enhances the management of the company's innovation work; organizes and coordinates other work on innovation evaluation of the company.

The internal accreditation body is an organization that will be set up in the future evaluation process and is mainly responsible for the extraction, review, implementation, and promotion of ideas. After the ideas submitted by the users, employees, experts, etc., collected, are refined and refined, proposals will be formed, which will then be deposited on the platform for review by the internal review committee. After these ideas are reviewed, ideas that match the company's value and are worthy of promotion will be promoted and eventually promoted on the platform.

\subsubsection{Knowledge Innovation Work Evaluation Index System}

For knowledge-creating work, it can be evaluated in three dimensions: input, process, and effectiveness [9].

Innovation investment includes organizational guarantees and resource guarantees. Organizational guarantees include innovations in the organizational structure and mechanisms, including two major tasks: First, establish leadership institutions for knowledge innovation, and improve the working mechanism, including the establishment of a leading group in this unit, and the chief responsible person as the first person responsible for knowledge innovation work. The responsible person in charge shall personally participate in and guide the advancement of knowledge innovation, establish and improve the working mechanism of information notification, inspection, assessment and evaluation; second, formulate annual opinions on knowledge innovation work, and opinions shall have clear ideas, goals, tasks, and time schedules, etc. The elements and working opinions must reflect the company's decision-making and deployment. The key work tasks are clear, pertinent and operational.

Resource protection also includes two aspects: First, the level of employee participation in knowledge innovation, that is, the number of employees participating in various types of knowledge innovation in the current year/the total number of employees*100\%; second, the proportion of knowledge innovation incentive investment in total cost, ie, The amount of investment in knowledge innovation awards for the current year/the total cost of the year* $100 \%$.

The innovation process includes project management and publicity training. The project refinement management includes: the level of knowledge innovation refinement, the level of knowledge innovation review, and the level of promotion of knowledge innovation achievements. Publicity training includes two aspects: First, the effectiveness of knowledge innovation and publicity work $(80 \%)$. The highlights of this unit's knowledge innovation are incorporated into the company's (local) work reports, information, and notifications, or publicity and reporting in the company's (local) newspapers, websites, etc.; the highlights of this unit's knowledge innovation are incorporated into the State Grid Corporation of China. Work reports, information, and notifications (at or above the provincial or ministerial level), or publicity and reporting in newspapers, websites, etc. of the State Grid Corporation (at or above the provincial level). The second is the rate of innovative knowledge training (20\%). Number of training courses organized by this unit on new knowledge, theory, or methods / Total number of training courses organized by the unit * 50\% + Employees participating in training on new knowledge, theory or methods, etc. Total staff time $* 50 \%$.

Finally, the results of knowledge innovation include awards, application of results, and results.

The entire "lead geese" talent training project is aimed at the common development of the company and its employees, and it has established an integrated employee career growth

\subsection{Knowledge Innovation Mechanism}

Incentive mechanism refers to the means and environment that can stimulate and guide people to produce specific behaviors. Establishing and improving incentive mechanisms is an effective means to mobilize the enthusiasm and creativity of talents and maximize their potential.

Incentive mechanism design is mainly based on positive incentives. It mainly includes Economic Value Award (EVA), One-time Award (LA), Ideas Award (AFI) and Best Practice Award. 
Among them, the economic value award for the innovative economic value brought about by the improvement and can be calculated, according to the economic value of discretion to give rewards; one-time award refers to the reward and economic value is not related to the creativity or EVA can not be calculated, reward 20-8000 yuan The idea prize means that improvement or creativity is not implemented but good attention is given to the idea. The Economic Value Award (EVA) and the One-time Award (LA) were introduced by the internal review committee and the Best Practice Award was launched.

\section{Electric power knowledge platform design}

\subsection{Platform design principles}

First of all, the design of the knowledge creation platform establishes the principle of "people-centered", which is embodied in encouraging users to share, allowing more people to participate, and making it easier for users to read:

(1) Users share. Under the Web 2.0 model, power users, power line workers, and power expert workers can share ideas without time and geographical constraints. Users can get the information they need and they can post their opinions. Makes the user a viewer of both the content of the site and the content of the site. This means that the Web 2.0 site provides users with more opportunities for participation. For example, blog sites and wikis are typical guidelines for user-generated content. The tag technology (user setting tag) directly assigns the information in the traditional website to the user.

(2) Many people participate. In Web1.0, Internet content is customized by a small number of editors (or webmasters), such as portals. In Web2.0, information is provided by organizations and individuals.

(3) In Web 1.0, the Internet is "reading Internet" and Web 2.0 is "readable and readable Internet." Although everyone participates in information feeds, it is a small part of people who, on a large scale, contribute most of their content.

Second, in order to realize the effect of knowledge change from quantitative to qualitative, the design of the platform establishes the principle of "information aggregation", which allows information to accumulate on the network and facilitates users to conduct historical queries to innovate on the basis of knowledge accumulation.

Thirdly, the platform for knowledge and creativity should be one of the manifestations of Crowd-innovating space. It should have "characteristics of popularity, openness, self-organization, and interaction" [10]. The third principle of creating a platform design is "establishing a community where interest is the aggregation point." Under the Web2.0 model, the knowledge crowdfunding platform can aggregate groups interested in one or more issues. These groups have higher frequency of knowledge exchange, higher content commonality, and are more likely to produce innovations in specific areas.

Finally, the knowledge-creating platform is based on the principle of enhancing interactivity, and has also done a lot of design in human-computer interaction and human-to-human interaction. This interactivity is not only reflected in the user's interaction with the web server in the process of publishing content, but also includes the interaction between different users of the same website and the interaction of information between different websites. Web2.0 includes the services we often use. BBS and blogs are the main representatives. The "one-to-many" and "many-to-many" modes of communication coexist. Examples include RSS, blogs, podcasts, wikis, P2P downloads, social bookmarking, SNS, communities, sharing services, and more. Blog is a very important element in Web2.0, because it breaks the information monopoly of the portal, and in the future, the status of blog will be more important. Web2.0 actually expands the information source of Web 1.0 to make it diversified and personalized.

\subsection{Platform technology}

The power knowledge crowdfunding platform adopts Web2.0 related technologies for design, including blogs, RSS, encyclopedias, online abstracts, social networks (SNS), P2P, and instant messaging (IM).

A blog is an easy-to-use website that allows users to quickly post ideas, communicate with others, and engage in other activities.

RSS is a simple technique (also called syndicated content) that sites use to share content with other sites. The technology originally derived from the browser "news channel" is commonly used for news and other inline websites such as blogs.

WIKI Encyclopedia, Wiki is a multi-person collaboration writing tool. Wiki sites can be maintained by multiple people (or even any visitor), and everyone can express their opinions or expand or explore common themes.

\subsection{Creative scene design}

Through research and interviews, we collected business requests from different users in the field of Jiangsu power marketing for the Knowledge Innovation platform. The first-line user's working environment was considered. The design of the system platform supports the convenient application of the mobile terminal. The crowded platform will be up to the enterprise management personnel, experts, business management personnel, down to the first-line power employees, new employees, etc. are included in the platform to use the object, to achieve from the front line to find problems, from the business to find a breakthrough in innovative models.

\subsection{Platform Functional Architecture}


In order to meet the needs of different groups of people, based on the principles and positioning of platform design, we incorporate the following major functions into the platform of knowledge and creativity: creating space, creative refinement, results promotion, and system management. The public space includes: mutual aid questions and answers, expert networks, wikis, etc. System management includes: space classification management, question and answer classification management, expert management, creative extraction management, and results promotion management. The functional structure of the system is shown in Figure 4.

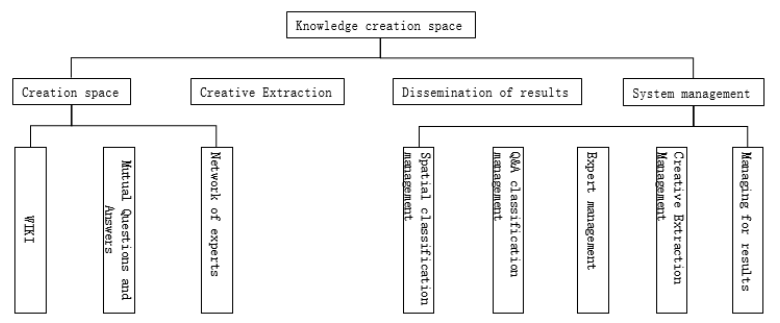

Fig. 3 China National Network Jiangsu Electric Power Knowledge Creation Platform Function

\section{Conclusion and outlook}

With the continuous innovation and development of information technology, the innovation model itself is also iteratively updating at a faster rate. The Zhongchuang mode is an innovative development mode that came into being in the context of the knowledge society, which effectively expanded the sources of innovation and enhanced the drive for innovation. This article takes Jiangsu State Power as the research object, specifically analyzes the development status of Jiangsu Electric Power Co., Ltd. of the State Grid and the conditions of the application of the crowd-building model, and designs the organizational structure and incentive mechanism of the crowd-sourced model applicable to power companies, and develops it in conjunction with Web 2.0. The knowledge-creating platform has added a detailed case for the application of the "Internet+Column" model. In the future, we can also analyze the application issues and solutions of the crowd-sourced model based on the operational effectiveness of the knowledge-based crowd-building platform, and form a set of perfect innovation models that meet China's national conditions and the development of the power system.

\section{References}

1. Chen Jin. Technological Innovation Studies for Super Innovative Nation [J]. Technology Economics, 2015 (34): 1-4

2. Liu Zhiying, Chen Qingxiang, $\mathrm{Xu}$ Yi. The Conceptual Model and Theoretical Analysis of Crowd Innovation $[\mathrm{J}]$. Science of Science and Management of S. \& T., 2015 (36): 52-61

3. Chesbrough, H. GE's ecomagination Challenge: An Experiment in Open Innovation, California Management Review [J], 2012 (3): 140-154

4. Wang guishan, Jin fu. The Model and Countermeasure of Intellectual Resources Management in High \&New Technological Enterprise $[\mathrm{J}]$. Science, Technology and Dialectics, 2006, 23(2):103-108.

5. Song gang, Zhang nan. Innovation 2.0: Democratizing Innovation in Knowledge Society [J]. China Soft Science, 2009(10): 60-66

6. Paul Griffiths and Teresita Arenas, 'ENTEL: A Case Study on Knowledge Networks and the Impact of Web 2.0 Technologies', Electronic Journal of eLearning [J], 2014 (12): 383-393.

7. Steven De Hertogh, Stijn Viaene, And Guido Dedene, 'Governing Web 2.0', Communications of The ACM, Business Source Complete [J], 2011(54):124-130.

8. Wang shushuang. Construction of Science and technology enterprise human resources management system [J]. Scientific Management Research, 2012, 30(6):94-97.

9. Xu liping, Jiang xiangrong, Yin chong. A research on the evaluation index system about innovation ability of enterprises [J]. Science Research Management, 2015(s1):122-126

10. $\mathrm{Fu}$ qunying, Liu zhiying. Crowd Innovating: Connotation and Operation Model[J]. Science of Science and Management of S. \& T., 2016(37): 3-10. 